\title{
Valores de energia metabolizável de alguns alimentos obtidos com aves de diferentes idades
}

\author{
Heloisa Helena de Carvalho Mello ${ }^{1}$, Paulo Cezar Gomes ${ }^{2}$, Horacio Santiago Rostagno ${ }^{2}$, Luiz \\ Fernando Teixeira Albino ${ }^{2}$, Renata Mara de Souza ${ }^{1}$, Arele Arlindo Calderano ${ }^{1}$
}

1 Pós-graduação em Zootecnia - UFV - Viçosa, MG.

${ }^{2}$ Departamento de Zootecnia - UFV - Viçosa, MG.

\begin{abstract}
RESUMO - Foram realizados quatro ensaios de metabolismo com a finalidade de determinar a energia metabolizável aparente (EMA) e a energia metabolizável aparente corrigida (EMAn) de dez alimentos em aves em diversas idades. Os alimentos testados foram: milho, farelo de soja, sorgo, farelo de trigo, farelo de arroz integral, duas farinhas de penas, duas farinhas de vísceras e plasma sangüíneo. Utilizou-se o método de coleta total de excretas, em delineamento experimental inteiramente casualizado, com 11 tratamentos (dez alimentos e uma ração-referência) e seis repetições. No primeiro ensaio, foram utilizados 528 pintos de corte machos de 10 a 17 dias de idade, totalizando oito aves por repetição; no segundo ensaio, 396 frangos de corte machos de 26 a 33 dias de idade, com seis aves por repetição; no terceiro ensaio, 264 frangos de corte machos de 40 a 47 dias de idade, com quatro aves por repetição; e, no quarto ensaio, 132 galos, com duas aves por repetição. A idade das aves influenciou os valores de EMA e EMAn do farelo de soja, do sorgo, do farelo de arroz integral, das farinhas de penas e do plasma sangüíneo, enquanto, para o farelo de trigo, teve efeito apenas sobre a EMAn.
\end{abstract}

Palavras-chave: composição química, energia metabolizável aparente, frangos de corte

\section{Metabolizable energy values of feedstuffs obtained from poultry at different ages}

\begin{abstract}
Four assays were carried out to determine the apparent metabolizable energy (AME) and the corrected apparent nitrogen metabolizable energy (AMEn) of ten feeds for poultry at different poultry ages. The feeds studied were: corn grain, soybean meal, ground sorghum, wheat bran, integral rice bran, two kinds of feather meal, two kinds of poultry viscera meal and spray-dried plasma. The method of total excreta collection was used to determine the AME and AMEn values. The broiler chicks were distributed on a completely randomized experimental design, with 11 treatments, six replications, with different number of animals by replication according to the assay. In the first assay, 528 male broiler chicks in the period from 10 to 17 days of age were used, with eight animals per replication. In the second assay, 396 male broiler chicks in the period from 26 to 33 days of age were used, with six animals per replication. In the third assay, 264 male broiler chicks in the period from 40 to 47 days of age were used, with four animals per replication. In the fourth assay, 132 roosters were used, with two animals per replicate. There was an effect of age on the AME and AMEn values of the following feeds: soybean meal, ground sorghum, integral rice bran, two kinds of feather meal and spray-dried plasma, where the oldest broilers provided the highest AME and AMEn values. Wheat bran was affected by age only for the AMEn values
\end{abstract}

Key Words: apparent metabolizable energy, broilers, chemical composition

\section{Introdução}

O consumo de carne de frango no Brasil apresentou nos anos de 1986 a 2006 crescimento de aproximadamente $400 \%$ (UBA, 2006). O conhecimento da composição química e energética dos ingredientes utilizados na formulação de rações é necessário para que se produzam rações com níveis nutricionais adequados para suprir as exigências dos animais, sem excesso ou deficiência, e permitir máxima produtividade.

A energia metabolizável (EM) é uma estimativa da energia dietética que está disponível para ser metabolizada pelo tecido animal. A determinação da energia metabolizável nas diferentes idades das aves torna-se importante, visto que a digestibilidade de energia tende a aumentar com a idade da ave, pois o trato digestivo se desenvolve, melho- 
rando sua capacidade de aproveitamento dos nutrientes e da energia dos alimentos. Segundo Sakomura et al. (2004), os menores valores de energia metabolizável determinados nas três primeiras semanas de idade das aves podem ser justificados pelos baixos coeficientes de digestibilidade do extrato etéreo nesta fase, assim como pelas baixas atividades da amilase e da lipase, de modo que nesse período a capacidade de digestão das aves não está totalmente desenvolvida, o que limita o aproveitamento dos nutrientes, principalmente gorduras, das dietas.

Para estimar com precisão os valores de energia metabolizável aparente (EMA), têm-se utilizado a correção pelo balanço de nitrogênio para obtenção da energia metabolizável aparente corrigida (EMAn). De acordo com Nery et al. (2007), o nitrogênio retido como tecido, se catabolizado, favorece as perdas de energia urinária endógena, contribuindo para variações nos valores de energia metabolizável aparente.

Além da idade, outros fatores afetam a utilização da energia metabolizável pelos animais, como peso corporal (Noblet \& Milgen, 2004), sexo das aves (Nascif et al., 2004), níveis de substituição do alimento testado na raçãoreferência (Nascimento et al., 2005), consumo (Albino, 1991), tipo e intensidade do processamento do alimento (Scapim et al., 2003), teores de vitaminas e microminerais da ração-teste (Ávila et al., 2006).

Objetivou-se com este trabalho determinar os valores de energia metabolizável aparente e energia metabolizável aparente corrigida do milho, farelo de soja, sorgo, farelo de trigo, farelo de arroz integral, da farinha de penas, farinha de vísceras e do plasma sangüíneo fornecidos às aves de diferentes idades.

\section{Material e Métodos}

Foram realizados quatro ensaios de metabolismo no Setor de Avicultura do Departamento de Zootecnia da Universidade Federal de Viçosa, no período de março a junho de 2006. Os ensaios foram conduzidos com pintos de corte da linhagem Ross machos com 10 a 17, de 26 a 33 e 40 a 47 dias de idade e galos Leghorn com 25 semanas de idade. Os alimentos testados foram: milho, farelo de soja, sorgo, farelo de trigo, farelo de arroz integral, duas farinhas de penas, duas farinhas de vísceras de aves e plasma sangüíneo.

Na determinação dos valores de energia metabolizável aparente (EMA) e aparente corrigida (EMAn), foi utilizado o método de coleta total de excretas. O período experimental foi de oito dias (três de adaptação e cinco de coleta de excretas) para cada ensaio.
$\mathrm{O}$ delineamento experimental utilizado em todos os ensaios foi o inteiramente casualizado, com 11 tratamentos e 6 repetições, com número variável de aves por unidade experimental, de acordo com o ensaio realizado. No primeiro ensaio, foram utilizados 528 pintos de corte com peso corporal de $160 \pm 0,3 \mathrm{~g}$, totalizando oito aves por unidade experimental; no segundo, 396 frangos de corte com peso corporal de $869 \pm 1,4 \mathrm{~g}$ (seis aves por unidade experimental); no terceiro, 264 frangos de corte com peso corporal de $2.037 \pm 7,5 \mathrm{~g}$ (quatro aves por unidade experimental); e, no quarto ensaio, 132 galos com peso corporal de $2.523 \pm 24 \mathrm{~g}$ (duas aves por unidade experimental).

Foram avaliados dez alimentos e uma ração-referência. Os alimentos de origem vegetal substituíram $40 \%$ da ração-referência e os de origem animal 25\%. Uma raçãoreferência (Tabela 1) foi utilizada nos três primeiros ensaios e outra no quarto ensaio (Tabela 2). Foram fornecidas ração e água à vontade.

Antes do início de cada ensaio de metabolismo, todas as aves receberam a mesma ração, segundo recomendações de Rostagno et al. (2005) para cada fase de criação.

Tabela 1 - Composição da ração-referência utilizada nos três primeiros ensaios, realizados com frangos de corte

\begin{tabular}{|c|c|}
\hline Ingrediente & $\%$ da matéria natural \\
\hline Milho & 55,87 \\
\hline Farelo de soja & 37,00 \\
\hline Fosfato bicálcico & 1,80 \\
\hline Óleo de soja & 3,00 \\
\hline Calcário & 1,10 \\
\hline Sal comum & 0,50 \\
\hline DL-metionina $(99 \%)$ & 0,21 \\
\hline L-lisina $\mathrm{HCl}(98 \%)$ & 0,20 \\
\hline 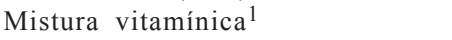 & 0,10 \\
\hline Mistura mineral $^{2}$ & 0,05 \\
\hline Salinomicina $12 \%$ & 0,05 \\
\hline Cloreto de colina $60 \%$ & 0,10 \\
\hline Avilamicina $10 \%$ & 0,01 \\
\hline Antioxidante (BHT) & 0,01 \\
\hline Total & 100,00 \\
\hline \multicolumn{2}{|l|}{ Composição calculada } \\
\hline Energia metabolizável (kcal/kg) & 2.987 \\
\hline Proteína bruta (\%) & 21,00 \\
\hline Lisina digestível (\%) & 1,20 \\
\hline Metionina + cistina digestível $(\%)$ & 0,80 \\
\hline Treonina digestível (\%) & 0,73 \\
\hline Triptofano digestível (\%) & 0,24 \\
\hline Cálcio (\%) & 1,00 \\
\hline Fósforo disponível (\%) & 0,42 \\
\hline Sódio (\%) & 0,21 \\
\hline \multicolumn{2}{|c|}{$\begin{array}{l}{ }^{1} \text { Composição por kg do produto: vit. A - } 12.000 .000 \mathrm{UI} \text {; vit. D3 - } 2.200 .000 \mathrm{UI} \text {; } \\
\text { vit. E - } 30.000 \mathrm{UI} \text {; vit. B1 - 2.200 mg; vit. B2 - } 6.000 \mathrm{mg} \text {; vit. B6 - } 3.300 \mathrm{mg} \text {; } \\
\text { ácido pantotênico - } 13.000 \mathrm{mg} \text {; biotina - } 110 \mathrm{mg} \text {; vit. K3 - } 2.500 \mathrm{mg} \text {; ácido } \\
\text { fólico - } 1.000 \mathrm{mg} \text {; ácido nicotínico - } 53.0000 \mathrm{mg} \text {; niacina - } 25.000 \mathrm{mg} \text {; vit. B12 - } \\
16.000 \mu \mathrm{gg} \text {; selênio - } 0,25 \mathrm{~g} \text {; antioxidante - } 120.000 \mathrm{mg} \text {; e veículo QSP. - } 1.000 \mathrm{~g} \\
{ }^{2} \text { Composição por kg do produto: manganês - } 75.000 \mathrm{mg} \text {; ferro - } 20.000 \mathrm{mg} \text {; zinco - } \\
50.000 \mathrm{mg} \text {; cobre - } 4.000 \mathrm{mg} \text {; cobalto - } 200 \mathrm{mg} \text {; iodo - } 1.500 \mathrm{mg} \text {; e veículo qsp - } \\
1.000 \mathrm{~g}\end{array}$} \\
\hline
\end{tabular}


Tabela 2 - Composição da ração-referência utilizada no quarto ensaio, realizado com galos

\begin{tabular}{|c|c|}
\hline Ingrediente & $\%$ da matéria natural \\
\hline Milho & 81,35 \\
\hline Farelo de soja & 15,12 \\
\hline Fosfato bicálcico & 1,39 \\
\hline Calcário & 0,46 \\
\hline Sal comum & 0,41 \\
\hline DL-metionina (99\%) & 0,24 \\
\hline L-lisina $\mathrm{HCl}(98 \%)$ & 0,43 \\
\hline L-treonina & 0,19 \\
\hline L-triptofano & 0,11 \\
\hline Mistura vitamínica ${ }^{1}$ & 0,10 \\
\hline Mistura mineral ${ }^{2}$ & 0,05 \\
\hline Salinomicina $12 \%$ & 0,05 \\
\hline Cloreto de colina $60 \%$ & 0,10 \\
\hline Total & 100,00 \\
\hline \multicolumn{2}{|l|}{ Composição calculada } \\
\hline Energia metabolizável (kcal/kg) & 3.091 \\
\hline Proteína bruta (\%) & 13,15 \\
\hline Lisina digestível (\%) & 0,50 \\
\hline Metionina + cistina digestível (\%) & 0,50 \\
\hline Treonina digestível (\%) & 0,40 \\
\hline Triptofano digestível (\%) & 0,15 \\
\hline Cálcio (\%) & 0,60 \\
\hline Fósforo disponível (\%) & 0,35 \\
\hline Sódio (\%) & 0,20 \\
\hline \multicolumn{2}{|c|}{$\begin{array}{l}{ }^{1} \text { Composição por kg do produto: vit. A - } 12.000 .000 \mathrm{UI} \text {; vit. D3 - } 2.200 .000 \mathrm{UI} \text {; } \\
\text { vit. E - } 30.000 \mathrm{UI} \text {; vit. B1 - 2.200 mg; vit. B2 - 6.000 mg; vit. B6 - 3.300 mg; } \\
\text { ácido pantotênico - } 13.000 \mathrm{mg} \text {; biotina - } 110 \mathrm{mg} \text {; vit. K3 - } 2.500 \mathrm{mg} \text {; ácido } \\
\text { fólico - } 1.000 \mathrm{mg} \text {; ácido nicotínico - } 53.0000 \mathrm{mg} \text {; niacina - } 25.000 \mathrm{mg} \text {;vit. B12 - }-1.000 \mathrm{~g} \text {. } \\
16.000 \mu \mathrm{g} \text {; selênio - } 0,25 \mathrm{~g} \text {; antioxidante - } 120.000 \mathrm{mg} \text {; e veículo QSP. - } 1.000 \text {. } \\
{ }^{2} \text { Composição por kg do produto: manganês }-75.000 \mathrm{mg} \text {; ferro - } 20.000 \mathrm{mg} \text {; zinco - } \\
50.000 \mathrm{mg} \text {; cobre - } 4.000 \mathrm{mg} \text {; cobalto - } 200 \mathrm{mg} \text {; iodo - } 1.500 \mathrm{mg} \text {; e veículo qsp - } \\
1.000 \mathrm{~g} \text {. }\end{array}$} \\
\hline
\end{tabular}

As unidades experimentais foram constituídas de gaiolas metabólicas providas de bandejas cobertas com plásticos com $8,6,4$ e 2 aves no $1^{\circ}, 2^{\circ}, 3^{\circ} \stackrel{\circ}{\text { e }} 4^{\circ}$ ensaios, respectivamente. A coleta de excretas foi feita duas vezes ao dia, uma às $8 \mathrm{~h}$ e outra às $17 \mathrm{~h}$, para evitar fermentação. O material coletado foi acondicionado em sacos plásticos devidamente identificados e armazenados em congelador.

Ao final de cada ensaio, as excretas foram pesadas, descongeladas e homogeneizadas. Uma amostra foi retirada e colocada em estufa de ventilação forçada a $55^{\circ} \mathrm{C}$ durante 72 horas para pré-secagem do material, necessária para as análises laboratoriais. Foi determinada a quantidade total de ração consumida por unidade experimental durante todo o período experimental de todos os ensaios de metabolismo.

As temperaturas máxima e mínima foram anotadas diariamente durante todo o período experimental.

As análises de composição química e energia bruta dos alimentos e de matéria seca, nitrogênio e energia bruta das rações e das excretas (Tabela 3) foram realizadas no Laboratório de Nutrição Animal do Departamento de Zootecnia da Universidade Federal de Viçosa, segundo metodologia descrita por Silva \& Queiroz (2002).

Os valores de energia metabolizável aparente (EMA) e energia metabolizável aparente corrigida (EMAn) foram calculados por meio de equações descritas por Matterson et al. (1965). Com base nos valores de energia bruta, EMA e EMAn, foram determinados os coeficientes de metabolizabilidade da energia dos alimentos.

As análises estatísticas foram realizadas por meio do programa SAEG - Sistema Para Análises Estatísticas Universidade Federal de Viçosa (2001), com análise de variância conjunta. Para verificar os efeitos da idade da ave sobre os valores de EMA, EMAn e os coeficientes de metabolizabilidade da energia para cada alimento, foi utilizado o teste Tukey a $5 \%$ de probabilidade.

\section{Resultados e Discussão}

O teor de proteína bruta $(\mathrm{PB})$ do milho foi inferior ao citado por Rostagno et al. (2005) (Tabela 3). Segundo Kato (2005), a freqüência com que são realizadas as adubações nitrogenadas influencia os teores de proteína bruta do grão de milho. O teor de fibra em detergente neutro (FDN) do milho foi superior ao encontrado por Rostagno et al. (2005) e semelhante ao citado por Rodrigues et al. (2001).

Os teores de FDN e fibra em detergente ácido (FDA) do farelo de soja foram semelhantes aos encontrados por Ost et al. (2005). Os farelos de soja de origens diversas podem

Tabela 3 - Composição química e valores de energia bruta dos alimentos, expressos na matéria natural

\begin{tabular}{|c|c|c|c|c|c|c|c|c|c|c|}
\hline Alimento & MS (\%) & PB (\%) & $\mathrm{EE}(\%)$ & MM (\%) & $\mathrm{Ca}(\%)$ & $\mathrm{P}(\%)$ & FB $(\%)$ & FDN $(\%)$ & FDA $(\%)$ & EB $(\mathrm{kcal} / \mathrm{kg})$ \\
\hline Farelo de soja & 87,45 & 44,38 & 1,3 & 5,01 & 0,15 & 0,35 & 6,20 & 10,66 & 6,92 & 4.017 \\
\hline Farelo de trigo & 89,19 & 15,28 & 2,32 & 4,67 & 0,09 & 0,84 & 8,80 & 38,43 & 11,78 & 3.945 \\
\hline Farelo de arroz integral & 90,71 & 13,36 & 13,13 & 9,50 & 0,08 & 1,49 & 8,45 & 22,11 & 10,84 & 4.482 \\
\hline Farinha de penas 1 & 93,91 & 80,31 & 3,63 & 2,87 & 0,39 & 0,31 & - & - & - & 5.242 \\
\hline Farinha de penas 2 & 94,24 & 82,14 & 4,03 & 2,66 & 0,38 & 0,35 & - & - & - & 5.278 \\
\hline Plasma sangüíneo & 91,14 & 71,68 & 1,32 & 8,55 & 0,15 & 0,49 & $\begin{array}{c}- \\
-\end{array}$ & $\begin{array}{c}- \\
-\end{array}$ & - & 4.604 \\
\hline
\end{tabular}


diferir quanto ao teor de casca, o que interfere nos valores de PB e fibra deste alimento, uma vez que os farelos com maior proporção de casca possuem maior teor de fibra e menor teor de proteína bruta.

Os teores de fibra bruta (FB), FDN e FDA do farelo de trigo analisados foram maiores que os do NRC (1994), enquanto o teor de extrato etéreo (EE) foi inferior. Segundo Nascimento et al. (1998), o tipo de processamento pode afetar o teor de extrato etéreo e fibra bruta dos alimentos.

As farinhas de penas 1 e 2 apresentaram teores de matéria seca (MS), proteína bruta e matéria mineral (MM) dentro dos valores especificados pela ANFAR (1985), porém o teor de extrato etéreo foi superior ao limite máximo especificado, de 2,5\%. Moritz \& Latshaw (2001) afirmaram que as condições de processamento afetam a qualidade da farinha, pois a adição de gordura, partes não-comestíveis e ossos na farinha pode afetar seu valor nutricional.

Os valores de PB das farinhas de vísceras 1 e 2 ficaram abaixo daquele especificado pela ANFAR (1985), de 65\%, enquanto os teores de matéria mineral foram superiores. Esses dados foram semelhantes aos obtidos por Nunes et al. (2005), que também encontraram menor valor de PB e maior teor de matéria mineral da farinha de vísceras que os da ANFAR (1985). A farinha de vísceras é resultante da prensagem e cocção de vísceras de aves e inclui cabeças e pés, o que pode ter alterado os teores de matéria mineral e proteína bruta desta farinha.

O valor de matéria mineral encontrado para o plasma sangüíneo foi semelhante ao citado por D'Agostini et al. (2004). Houve efeito $(\mathrm{P}<0,05)$ da idade sobre os valores de EMA e EMAn do farelo de soja, do sorgo, das farinhas de penas 1 e 2 e do plasma sangüíneo (Tabela 4), que foram maiores quando determinados com aves mais velhas. Esses dados estão de acordo com os descritos por Batal \& Parsons (2003). Para o farelo de trigo, houve efeito da idade apenas sobre o valor de EMAn. Os valores de EMA e de EMAn do farelo de arroz integral não diferiram entre si quando determinados com frangos, mas foram maiores quando determinados com galos. Batal \& Parsons (2002) afirmaram que as digestibilidades do amido e da gordura aumentam com a idade, causando o aumento da EMAn.

Os valores de EMA e de EMAn do farelo de soja, das farinhas de penas 1 e 2 e do plasma sanguíneo aumentaram a partir de 26 dias de idade, quando permaneceram todos iguais em todas as idades, com exceção do plasma sangüíneo. Sakomura et al. (2004) encontraram aumento linear da atividade da amilase, da tripsina e da lipase com o avançar da idade da ave e a fase de maior aumento ocorreu entre a primeira e a segunda semana de idade, coincidindo com o máximo crescimento alométrico do pâncreas. Isso evidencia a influência da idade das aves no aproveitamento da energia dos alimentos, de acordo com a produção das enzimas digestivas.

Os valores de EMA e de EMAn (Tabela 4) obtidos para o farelo de soja nos frangos com 10 a 17 dias de idade foram inferiores aos encontrados nas outras fases e em galos. Os oligossacarídeos presentes no farelo de soja aumentam a viscosidade da digesta, o que dificulta o contato das enzimas digestivas com os nutrientes, prejudicando sua digestibilidade.

O coeficiente de metabolizabilidade da energia bruta do milho aumentou de 79,0 para 84,1 em comparação a frangos de até 33 dias com frangos até 47 dias de idade e galos adultos (Tabela 5). Isto evidencia melhora na digestibilidade dos carboidratos presentes no milho. Batal \& Parsons (2004), estudando o efeito da idade sobre a digestibilidade dos carboidratos, verificaram que os valores de EMAn do milho aumentaram de 12 a $15 \%$ com o decorrer da idade.

Em frangos com 10 a 17 dias, os valores de EMA do sorgo foram inferiores $(\mathrm{P}<0,05)$ aos encontrados nos frangos

Tabela 4 - Valores de energia metabolizável aparente (EMA) e aparente corrigida (EMAn) dos alimentos de aves de diversas idades, expressos na matéria natural ${ }^{1}$

\begin{tabular}{|c|c|c|c|c|c|c|c|c|}
\hline \multirow[t]{2}{*}{ Alimento } & \multicolumn{4}{|c|}{ EMA (kcal/kg) } & \multicolumn{4}{|c|}{ EMAn (kcal/kg) } \\
\hline & 10 a 17 dias & 26 a 33 dias & 40 a 47 dias & Galos & 10 a 17 dias & 26 a 33 dias & 40 a 47 dias & Galos \\
\hline Milho & 3.167 & 3.144 & 3.390 & 3.371 & 3.168 & 3.135 & 3.389 & 3.364 \\
\hline Farelo de soja & $1.759 \mathrm{~b}$ & $2.206 \mathrm{a}$ & $2.247 \mathrm{a}$ & $2.165 \mathrm{a}$ & $1.748 \mathrm{~B}$ & $2.192 \mathrm{~A}$ & $2.236 \mathrm{~A}$ & $2.153 \mathrm{~A}$ \\
\hline Sorgo & $2.738 b$ & $3.019 \mathrm{ab}$ & $3.091 \mathrm{a}$ & $3.303 \mathrm{a}$ & $2.732 \mathrm{~B}$ & $3.012 \mathrm{AB}$ & $3.088 \mathrm{~A}$ & $3.296 \mathrm{~A}$ \\
\hline Farelo de trigo & 1.588 & 1.624 & 1.739 & 1.925 & $1.579 \mathrm{~B}$ & $1.621 \mathrm{AB}$ & $1.738 \mathrm{AB}$ & $1.921 \mathrm{~A}$ \\
\hline Farelo de arroz integral & $2.111 \mathrm{~b}$ & $2.143 b$ & $2.047 \mathrm{~b}$ & $2.615 \mathrm{a}$ & $2.105 \mathrm{~B}$ & $2.137 \mathrm{~B}$ & $2.047 \mathrm{~B}$ & $2.611 \mathrm{~A}$ \\
\hline Farinha de penas 1 & $2.633 b$ & $3.071 \mathrm{a}$ & $3.166 \mathrm{a}$ & $3.247 \mathrm{a}$ & $2.607 \mathrm{~B}$ & $3.039 \mathrm{~A}$ & $3.128 \mathrm{~A}$ & $3.216 \mathrm{~A}$ \\
\hline Farinha de penas 2 & $2.627 \mathrm{~b}$ & $3.274 \mathrm{a}$ & $3.391 \mathrm{a}$ & $3.239 \mathrm{a}$ & $2.599 \mathrm{~B}$ & $3.237 \mathrm{~A}$ & $3.347 \mathrm{~A}$ & $3.209 \mathrm{~A}$ \\
\hline Farinha de vísceras 1 & 3.889 & 3.924 & 4.024 & 4.039 & 3.860 & 3.891 & 3.992 & 4.009 \\
\hline Farinha de vísceras 2 & 3.992 & 3.854 & 3.863 & 3.896 & 3.959 & 3.822 & 3.837 & 3.874 \\
\hline Plasma sangüíneo & $2.805 b$ & $3.652 \mathrm{a}$ & $3.505 \mathrm{a}$ & $2.982 \mathrm{~b}$ & $2.776 \mathrm{~B}$ & $3.610 \mathrm{~A}$ & $3.461 \mathrm{~A}$ & $2.962 \mathrm{~B}$ \\
\hline
\end{tabular}

${ }^{1}$ Médias seguidas por letras diferentes na linha, em cada parâmetro, diferem $(\mathrm{P}<0,05)$ entre si pelo teste Tukey. 
Tabela 5 - Coeficientes de metabolizabilidade aparente (CMA) e aparente corrigida (CMAn) dos alimentos em aves de diversas idades, expressos na matéria natural ${ }^{1}$

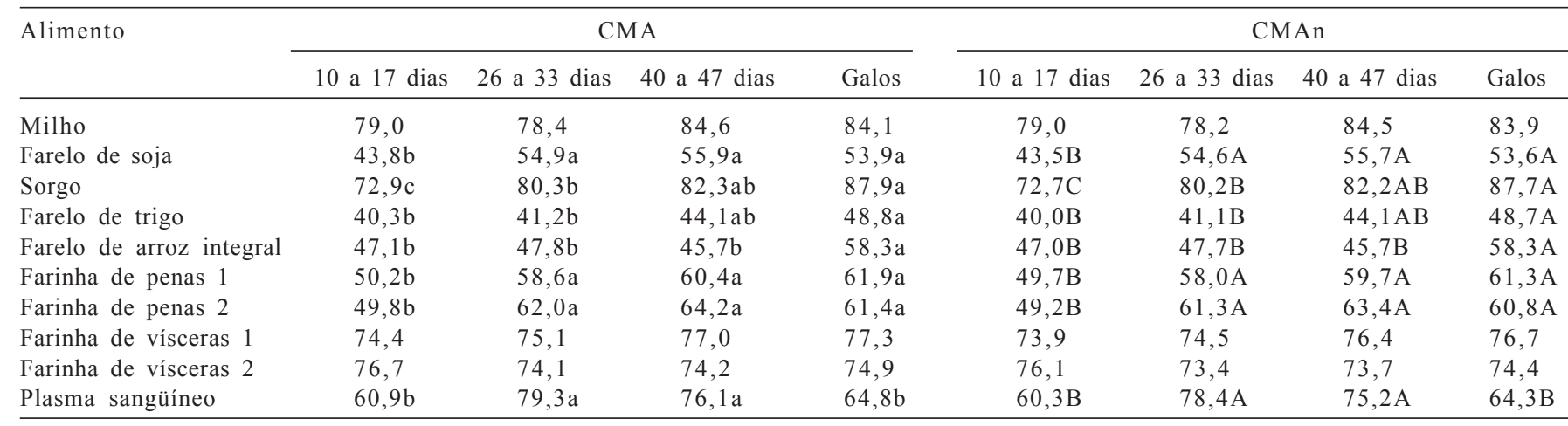

${ }^{1}$ Médias seguidas de letras diferentes na linha, em cada parâmetro, diferem $(\mathrm{P}<0,05)$ entre si pelo teste Tukey.

com 40 a 47 dias de idade e com galos. O grânulo de amido presente no sorgo é encapsulado por uma rígida matriz protéica, o que dificulta a ação enzimática e piora a digestibilidade, principalmente nas primeiras semanas de vida das aves. A metabolizabilidade da energia bruta do sorgo foi inferior à do milho somente nas idades de 10 a 17 dias. Segundo Scheuermann (1998), os teores de energia metabolizável de sorgo sem tanino, para aves, estão muito próximos dos valores do milho.

$\mathrm{O}$ valor de EMAn do farelo de trigo determinado para galos adultos foi $21,65 \%$ maior que para frangos de 10 a 17 dias de idade. Quando determinados com frangos de 40 a 47 dias de idade, os valores de EMA e de EMAn do farelo de trigo foram semelhantes aos citados por Nunes et al. (2001), de 1.742 e $1.711 \mathrm{kcal} / \mathrm{kg}$.

Entre os alimentos de origem vegetal estudados, os menores coeficientes de metabolizabilidade da energia bruta foram obtidos com o farelo de trigo, provavelmente em razão dos altos teores de FB, FDN e FDA presentes neste alimento. Além disso, o farelo de trigo possui altas quantidades de polissacarídeos não-amiláceos solúveis, que promovem o aumento da viscosidade da digesta, prejudicando a digestibilidade dos nutrientes. Segundo Conte et al. (2002), a energia metabolizável é afetada direta e positivamente pela composição do alimento em amido, gordura e proteína e negativamente pelos carboidratos estruturais.

O farelo de arroz apresentou alto teor de matéria mineral (9,5\%), o que, segundo Paula et al. (2002), causa menor digestibilidade da proteína. Alguns fatores antinutricionais também podem afetar a digestibilidade do farelo de arroz integral. Segundo Schoulten et al. (2003), altas porcentagens de ácido fítico e fibra solúvel no farelo de arroz prejudicam a digestibilidade de todos os componentes nutritivos da dieta.
Entre os alimentos de origem animal estudados, as farinhas de penas 1 e 2 foram aqueles com menores coeficientes de metabolizabilidade da energia bruta. De acordo com Nunes et al. (2006), as farinhas de penas geralmente são ricas em proteínas estruturais resistentes e insolúveis, denominadas queratina, que podem resultar em baixos valores de metabolizabilidade.

Os valores de EMAn das farinhas de vísceras 1 e 2 foram superiores aos descritos por Rostagno et al. (2005), Nunes et al. (2005) e Tucci et al. (2003), de 3.579, 2.384 e $3.636 \mathrm{kcal} / \mathrm{kg}$, respectivamente, uma vez que as farinhas de vísceras estudadas neste trabalho apresentaram valores de energia bruta superiores aos encontrados por esses autores.

Verificou-se baixo consumo dos galos para o plasma sanguíneo, o que pode ter afetado os valores energéticos obtidos para esse alimento. Segundo Albino (1991), as variações do conteúdo de energia dos alimentos estão diretamente relacionadas ao consumo de alimento, desta forma, valores de EMA são subestimados quando há redução do consumo do alimento. Os valores de EMA e de EMAn do plasma sangüíneo obtidos com frangos nas idades de 26 a 33 e 40 a 47 dias de idade estão de acordo com os reportados por D'Agostini et al. (2004), de 3.503 e $3.474 \mathrm{kcal} / \mathrm{kg}$, e foram superiores aos encontrados por Brumano et al. (2006), de 3.006 e $2.673 \mathrm{kcal} / \mathrm{kg}$.

\section{Conclusões}

Os valores de EMA do farelo de soja, do sorgo, do farelo de arroz integral, das farinhas de penas e do plasma sangüíneo e os valores de EMAn desses alimentos, assim como os do farelo de trigo, aumentam de acordo com a idade das aves. Portanto, ao formular rações para aves, deve-se considerar que os valores energéticos dos alimentos diferem em cada idade. 


\section{Literatura Citada}

ALBINO, L.F.T. Sistemas de avaliação nutricional de alimentos e suas aplicações na formulação de rações para frangos de corte. 1991. 141f. Tese (Doutorado em Zootecnia) - Universidade Federal de Viçosa, Viçosa, MG, 1991.

ASSOCIAÇÃO NACIONAL DOS FABRICANTES DE RAÇÕESANFAR. Matérias-primas para alimentação animal. 4.ed. São Paulo: 1985. 65p.

ÁVILA, V.S.; PAULA, A.; BRUM, P.A.R. et al. Uso da metodologia de coleta total de excretas na determinação de energia metabolizável em rações para frangos de corte ajustadas ou não quanto aos níveis de vitaminas e minerais. Revista Brasileira de Zootecnia, v.35, n.4, p.1691-1695, 2006 (supl).

BATAL, A.B.; PARSONS, C.M. Effects of age on nutrient digestibility in chicks fed different diets. Poultry Science, v. 81, p.400-407, 2002.

BATAL, A.B.; PARSONS, C.M. Utilization of different soy products as affected by age in chicks. Poultry Science, v.82, p.454462, 2003

BATAL, A.B.; PARSONS, C.M. Utilization of various carbohydrate sources as affected by age in the chick. Poultry Science, v.83, p.1140-1147, 2004.

BRUMANO, G.; GOMES, P.C.; ALBINO, L.F.T. et al. Composição química e valores de energia metabolizável de alimentos protéicos determinados com frangos de corte em diferentes idades. Revista Brasileira de Zootecnia, v.35, n.6, p.2297-2302, 2006.

CONTE, A.J.; TEIXEIRA, A.S.; BERTECHINI, A.G. et al.. Efeito da fitase e xilanase sobre a energia metabolizável do farelo de arroz integral em frangos de corte. Ciência e Agrotecnologia, v.26, n.6, p.1289-1296, 2002.

D'AGostini, P.; GOMES, P.C.; AlbinO, L.F.T. Valores de composição química e energética de alguns alimentos para aves. Revista Brasileira de Zootecnia, v.33, n.1, p.128-134, 2004.

EMPRESA BRASILEIRA DE PESQUISA AGROPECUÁRIA EMBRAPA. Tabelas de composição química e valores energéticos de alimentos para suínos e aves. 3.ed. Concórdia: CNPSA, 1991. 97p. (Documento, 19).

KATO, R.K. Energia metabolizável de alguns ingredientes para frangos de corte em diferentes idades. 2005. $96 \mathrm{f}$. Tese (Doutorado em Zootecnia) - Universidade Federal de Lavras, Lavras, 2005.

MATTERSON, L.S.; POTTER, L.M.; STUTZ, M.W. et al. The metabolizable energy of feed ingredients for chickens. University of Connecticut Storrs: Agricultural Experiment Station, 1965. v.11, 11p. (Research Report).

MORITZ, J.S.; LATSHAW, J.D. Indicators of nutritional value of hydrolyzed feather meal. Poultry Science, v.80, p.79-86, 2001.

NASCIF, C.C.C.; GOMES, P.C.; ALBINO, L.F.T. Determinação dos valores energéticos de alguns óleos e gorduras para pintos de corte machos e fêmeas aos 21 dias de idade. Revista Brasileira de Zootecnia, v.33, n.2, p.375-385, 2004

NASCIMENTO, A.H.; GOMES, P.C.; ALBINO, L.F.T. et al.. Valores de composição química e energética de alimentos para frangos de corte. Revista Brasileira de Zootecnia, v.27, n.3, p.579-583, 1998.

NASCIMENTO, A.H.; GOMES, P.C., ROSTAGNO, H.S. et al. Valores de energia metabolizável de farinhas de penas e de vísceras determinados com diferentes níveis de inclusão e duas idades das aves. Revista Brasileira de Zootecnia, v.34, n.3, p. $877-871,2005$.

NATIONAL RESEARCH COUNCIL - NRC. Nutrient requirements of poultry. 9.ed. Washington, D.C.: National Academy Press, 1994. $176 \mathrm{p}$.
NERY, L.R.; ALBINO, L.F.T.; ROSTAGNO, H.S. et al. Valores de energia metabolizável de alimentos determinados com frangos de corte. Revista Brasileira de Zootecnia, v.36, n.5, p.1354-1358, 2007.

NOBLET, J.; MILGEN, J. Energy value of pig feeds: effect of pig body weight and energy evaluation system. Journal of Animal Science, v.82, p.229-238, 2004 (suppl.).

NUNES, R.V.; ROSTAGNO, H.S.; ALBINO, L.F.T. et al. Composição bromatológica, energia metabolizável e equações de predição da energia do grão e de subprodutos do trigo para pintos de corte. Revista Brasileira de Zootecnia, v.30, n.3, p.785-793, 2001.

NUNES, R.V.; POZZA, P.C.; NUNES, C.G.V. et al. Valores energéticos de subprodutos de origem animal para aves. Revista Brasileira de Zootecnia, v.34, n.4, p.1217-1224, 2005.

NUNES, R.V.; ROSTAGNO, H.S.; GOMES, P.C. et al. Valores energéticos de diferentes alimentos de origem animal para aves. Revista Brasileira de Zootecnia, v.35, n.4, p.1752-1757, 2006 (supl.).

OST, P.R.; RODRIGUES, P.B.; FIALHO, E.T. et al. Valores energéticos de sojas integrais e de farelos de soja, determinados com galos adultos e por equações de predição. Ciência e Agrotecnologia, v.29, n.2, p.467-475, 2005

PAULA, A.; BRUM, P.A.R.; ÁVILA, V.S. et al. Valores de energia metabolizável da farinha de carne e ossos e farinha de vísceras determinados com diferentes níveis de substituição para frangos de corte. Revista Brasileira de Agrociência, v. 8 n.1, p.51-55, 2002.

RODRIGUES, P.B.; ROSTAGNO, H.S.; ALBINO, L.F.T. et al. Valores energéticos do milheto, do milho e subprodutos do milho, determinados com frangos de corte e galos adultos. Revista Brasileira de Zootecnia, v.30, n.6, p.1767-1778, 2001

ROSTAGNO, H.S.; ALBINO, L.F.T.; DONZELE, J.L. et al. Tabelas brasileiras para aves e suínos: composição de alimentos e exigências nutricionais. Viçosa, MG: Editora UFV, 2005. 186p.

SAKOMURA, N.K.; BIANCHI, M.D.; PIZAURO JR., J.M. et al. Efeito da idade dos frangos de corte na atividade enzimática e digestibilidade dos nutrientes do farelo de soja e soja integral. Revista Brasileira de Zootecnia, v.33, n.4, p.924-935, 2004.

SCAPIM, M.R.S.; LOURES, E.G.; ROSTAGNO, H.S. et al. Avaliação nutricional da farinha de penas e de sangue para frangos de corte submetida a diferentes tratamentos térmicos. Acta Scientiarum.Animal Sciences, v.25, n.1, p.91-98, 2003.

SCHEUERMANN, G.N. Utilização do sorgo em rações para frangos de corte. Concórdia: Embrapa Suínos e Aves, 1998. (Instrução técnica para o avicultor). 3p.

SCHOULTEN, N.A.; TEIXEIRA, A.S.; RODRIGUES, P.B. et al. Desempenho de frangos de corte alimentados com ração contendo farelo de arroz e enzimas. Ciência e Agrotecnologia, v.27, n.6, p.1380-1387, 2003.

SILVA, D.J.; QUEIROZ, A.C. Análise de alimentos (métodos químicos e biológicos). 3.ed. Viçosa, MG: Editora UFV, 2002. 235p.

TUCCI, F.M.; LAURENTIZ, A.C.; SANTOS, E.A. Determinação da composição química e dos valores energéticos de alguns alimentos para aves. Acta Scientiarum.Animal Sciences, v. 25, n. 1, p. 85-89, 2003.

UNIÃO BRASILEIRA DE AVICULTURA. Relatório anual 2005/ 2006. Disponível em: $<$ http://www.uba.org.br/ubanews_files/ rel uba 2005 06.pdf $>$, Acesso em:1/3/2007.

UNIVERSIDADE FEDERAL DE VIÇOSA- UFV. SAEG - Sistema para análises estatísticas. versão 9.0. Viçosa, MG: Universidade Federal de Viçosa, 2001. (CD-ROM). 